\title{
Microstructural Evolution in Thermal Cycles of Continuous Cooling in a Pressure Vessel Steel SA580 Grade 3 Class 1
}

\author{
Martin J. Iofrida ${ }^{1 *}$, María I. Luppo ${ }^{1}$ and Claudio A. Danón ${ }^{1}$ \\ 1. National Atomic Energy Commission (CNEA), Materials Management, Buenos Aires, Argentina. \\ * Corresponding author: martiniofrida@cnea.gov.ar
}

The manufacturing process of metallic structural components, such as nuclear reactors pressure vessels, involves the challenge of providing homogeneous properties through large thicknesses. Small variations in parameters such as chemical composition are reflected in the behavior in transformation and microstructural evolution.

SA 508 Gr. $3 \mathrm{Cl} .1$ steels with manufacturing process (quenching and tempering) and chemical composition given according to the ASME code, are frequently used in pressure vessels.

In order to meet the expected microstructures in each thermal cycle, it is necessary to build a Continuous Cooling Transformation Diagram for each case because they are valid under restricted conditions.

A study of the microstructural evolution of the presented steel was performed, combining dilatometry with scanning electron microscopy (SEM) in thermal cycles with the following characteristics: (i) heating rate of $10{ }^{\circ} \mathrm{C} / \mathrm{s}$, (ii) austenization at $920{ }^{\circ} \mathrm{C}$ during 10 minutes and (iii) continuous cooling at speeds of $0.1,1,10,20,30$ and $40^{\circ} \mathrm{C} / \mathrm{s}$.

The experiments were performed using a high resolution quench dilatometer, Bähr DIL 805 A with cylindrical samples. For the metallographic analysis, the median longitudinal plane of each sample was examined by Scanning Electron Microscopy using a FE-SEM Zeiss Supra 40.

The metallographic analysis in the different specimens allowed to distinguish, ferritic (F), bainitic (B) and martensitic (M) structures, as shown in Figure 1 with the corresponding transformation temperatures obtained from the dilatometric curves.

Results obtained are consistent with the microstructures observed for each case and has similar characteristics with references for the same material in similar thermal cycles.

\section{References:}

[1] ASME, Boiler and Pressure Vessel Code, Sec. 2, Part. A, Gr. 2, (2010), pp. 897-906.

[2] K. Suzuki, et al., Nuclear Engineering and Design, Vol. 206, (2001), pp. 261-278. 

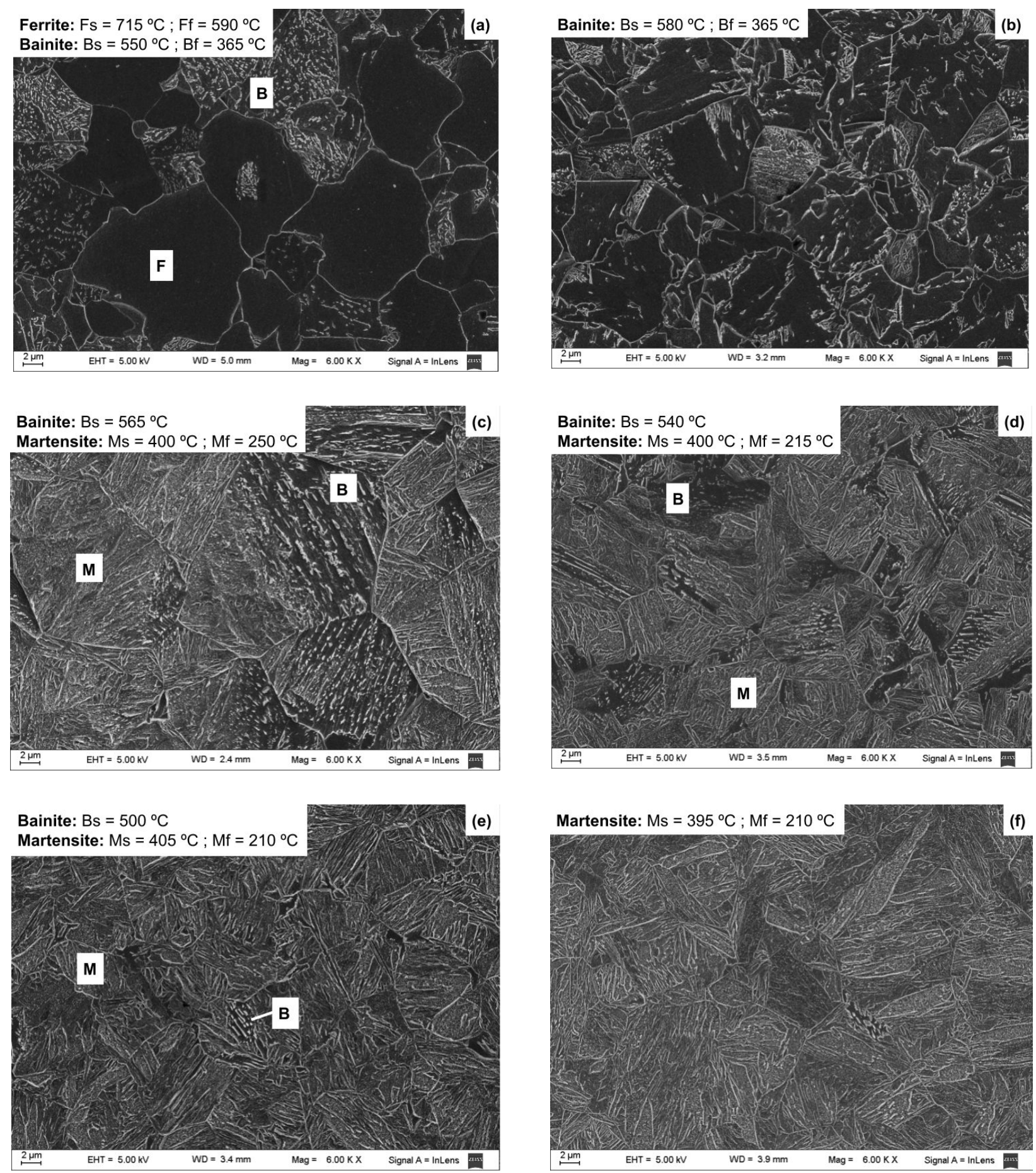

Figure 1: SEM images for samples cooled at (a) 0.1 , (b) 1, (c) 10, (d) 20, (e) $30 \mathrm{y} \mathrm{(f)} 40^{\circ} \mathrm{C} / \mathrm{s}$. 